\title{
Sobre as Influências Na Formação do Geógrafo Físico a Partir das Contribuições da Geografia de Matriz Anglo-Saxã
}

\author{
On The Influences In The Training of The Physical Geographer From \\ The Contributions of An Anglo-Saxon Geographical Matrix
}

\author{
Antonio Carlos de Barros Correa ${ }^{1}$, Kleython de Araujo Monteiro ${ }^{2}$ \\ 1 Universidade Federal de Pernambuco, dbiase2001@terra.com.br \\ 2 Universidade Federal de Alagoas, kleython.monteiro@igdema.ufal.br
}

Recebido (Received): 20/07/2018

Aceito (Accepted): 23/08/2018

\begin{abstract}
Resumo: A geografia física brasileira, sobretudo após a difusão da linguagem matematizada e estatística conquanto, seja sobre uma base teórica sistêmica ou de busca direta de relações causais, mediada pelo crescente aporte da modelagem em bases digitais, efetuou de forma deliberada ou não uma aproximação à geografia física de matriz anglo-saxã, de tradição fortemente empiricista. O marco dessa vertente foi a emergência da diatribe entre a valoração do tempo e os demais elementos envolvidos na explicação espacial. Sua suplantação, em prol do papel dos processos superficiais e suas magnitudes de ocorrência, a partir da segunda metade do século XX, esteve atrelada a importantes mudanças na história social e suas reverberações sobre a ciência e seus objetivos finais. Contemporaneamente, uma retomada da variável tempo é seguida pela modulação dessa à necessidades temáticas dos estudos geográficos, e não mais como uma categoria à priori. A geografía física de matriz anglo-saxã, altamente dependente da técnica, reflete atualmente, como é o caso de outras ciências históricas de interface experimental, a dependência do método científico e da emergência de situações problemas.
\end{abstract}

Palavras-chave: Ciência histórica; Teoria Geográfica; Geografia Física; Geografia Histórica.

\begin{abstract}
Brazilian physical geography, especially after the diffusion of a mathematical and statistical approach, whether upon a systems theoretical standpoint or the direct search for causal relationships, assisted by the growing support of digital modeling, has come close, deliberately or not, to the Anglo-Saxon, highly empirical, geographical tradition. A landmark of this affiliation was the emergence of a long-standing diatribe between the appreciation of time over other elements involved in the spatial explanation. Its overcoming, in favor of surficial processes of different operational magnitudes, following the second half of the 20th Century, was linked to important changes in social history and their reverberations on Science and its final aims. Contemporarily, a revival of time as a significant variable is accompanied by its adjustment to the thematic necessities of the geographical studies, therefore not a taken for granted a priori category. Physical geography of Anglo-Saxon derivation is highly dependent on technique, and lately reflects, as do other historical sciences with experimental interfaces, a dependence on the scientific method and the rise of problem situations.
\end{abstract}

Keywords: Historical Science; Geographical Theory; Physical Geography; Historical Geography.

\section{Introdução}

Assim como se tem procedido em outras áreas do conhecimento, a premissa norteadora desta reflexão recai no fato de que as mudanças nas visões de mundo prevalecentes sobre a natureza comandam as explicações sobre as características, funcionamento, utilização, percepção e treinamento acadêmico e profissional em geografia física. Da mesma forma, essas percepções cambiantes atuaram sobre a valorização e a tomada de decisões dos grupos sociais acerca do seu suporte natural no transcurso do tempo. 
$\mathrm{Na}$ trilha de outras sínteses sobre o papel da geografia física dentro do conjunto da ciência geográfica, a partir de um ponto de vista que considera as práticas da geografia brasileira, como as contribuições de Mendonça (1998), Suertegaray (2002) e Conti (2005), este trabalho busca resgatar algumas influências da matriz anglo-saxã da geografia física, que no Brasil foi de fundamental importância para a construção de algumas tradições de pesquisa, passando desde os trabalhos de ruptura paradigmática do Prof. Antonio Christofoletti e colaboradores no centro-sul, à formação de mais de uma geração de geógrafos do Nordeste do país, como é o caso de Pernambuco, desde o estabelecimento do seu primeiro curso de geografia no início da década de 1950.

No decorrer deste ensaio, se adotou a posição de que a geografia física não pode ser separada dos contextos da história social, de onde a mesma é praticada, o que se reflete nas significativas mudanças no tipo de explicação geográfica oferecida a cada momento, mais do que nas transformações metodológicas e técnicas ocorridas dentro dessa ciência. A história inclui desenvolvimentos políticos, sociais, econômicos e científicos, e a geografia física não existe em um vácuo histórico-conceitual.

Como já enunciado, escolhemos para os fins desta contribuição o papel do treinamento em geografia física a partir de uma contribuição das tradições anglo-saxãs, onde esse ramo da geografia tem demonstrado grande vitalidade, tanto na produção científica quanto na preparação de novos geógrafos e pesquisadores, seguramente para além de seus estritos domínios geográficos, e mesmo em escolas onde mais de uma tradição de formação se sobrepõem.

Assim, retomando a questão do treinamento e formação acadêmica do geógrafo físico, tem-se que obrigatoriamente ir além da sistematização dos primeiros departamentos acadêmicos de geografia nas universidades europeias a partir do último quartel do século XIX. Desta forma, não se abre mão da visão de que mesmo antes da institucionalização, o processo de formação de uma determinada atitude sobre os conteúdos geográficos, e em particular sobre os aspectos físico-naturais do espaço, já estava imbuído das características e preocupações de construção do conhecimento em cada momento histórico.

Dentro da perspectiva assinalada acima, as viagens de naturalistas anglo-saxões ao Brasil ao longo do período colonial e do Império deixaram um legado, ainda que incompleto, de observações sobre a paisagem física que reflete uma clara inclinação pela busca de explicações mediadas pela observação dos fenômenos naturais, para além da descrição e da catalogação das formas de vida. Embora fragmentárias e espacialmente dispersas, algumas dessas contribuições tiveram importante impacto na compreensão de processos formativos da superfície terrestre, como é o caso da elaborada explanação oferecida por Charles Darwin em 1832 sobre a origem dos arrecifes que balizam a entrada do porto do Recife (DARWIN, 1839)

Ainda nessa linha de contribuição, a expedição do naturalista suíço-americano Louis Agassiz, parcialmente comissionada pelo Imperador Dom Pedro II, em 1865 para proceder a coleta de espécimes para a montagem de uma "Coleção Brasileira" no museu de História Natural de Harvard, não foi destituída de um espírito formativo, uma vez que os membros da equipe, selecionados por Agassiz, eram treinados na taxonomia das formas de vida e expressões superficiais da crosta terrestre, elementos então essenciais à formação do naturalista/geógrafo físico. De fato, parte das observações de Agassiz algumas das primeiras tentativas de explicar em bases empíricas a gênese das formas de relevo do Brasil tropical Atlântico, as quais o autor buscou encaixar dentro da sua perspectiva de catastrofismo glacial (AGASSIZ E AGASSIZ, 1868).

Dando um salto no tempo, e buscando compreender como a visões da geografia física anglo-saxã, conquanto disciplina formativa, acompanharam de perto a ordem do dia das transformações sociais desde sua consolidação nos centros acadêmicos, nos debruçamos sobre o guia de disciplinas para o ano acadêmico 195051 do Departamento de Geografia da Universidade da Califórnia em Los Angeles (UCLA). A matriz curricular para a formação do bacharel em Geografia àquela altura já trazia como disciplinas obrigatórias epígrafes tais como: Conservação dos recursos naturais e Aspectos geográficos do planejamento de terras. Não coincidentemente essa grade curricular estava ancorada a uma escola cuja estrutura física passava então por tremendas transformações, com a ampliação dos espaços de estacionamento para alunos, construção de novos prédios e laboratórios, em um irrequieto contexto metropolitano em que surgiam as primeiras experiências de implantação de vias expressas urbanas de grande dimensão e conversão continua de áreas rurais em subúrbios interligados por tal sistema viário.

Obviamente as reverberações das transformações do espaço urbano entre as décadas de 1950 e 60, e a ação do planejamento territorial, estavam presentes em todos os cantos do globo, desde a concepção e implantação de Brasília, aos programas soviéticos de construção de moradias verticais em massa nas encostas íngremes da cidade portuária de Vladivostok. 
Lembramos, contudo, que compreendemos que a educação formal do geógrafo é essencialmente um construto ocidental. Suas raízes históricas, remontam principalmente ao resgate renascentista da contribuição de filósofos gregos clássicos, dentro da tradição sofista. Destarte, nossas considerações terão seu foco voltado ao treinamento formal em geografia física, evitando, ou apenas tangenciando, a ideia de que a geografia física pode também ser considerada como uma propriedade da cognição humana, que se expressa de forma furtiva e imprecisa, no estabelecimento de conexões entre elementos e fenômenos aparentemente não correlacionáveis (CLIFFORD, 2001).

Baker (2008), nos alerta que assim como existe um anseio humano básico pelo conhecimento do tempo e compreensão do passado, como resgate das nossas próprias histórias enquanto coletivo social, há, em contrapartida um anseio semelhante pelo entendimento dos lugares e as razões que determinam suas diferenças. Assim, poder-se-ia afirmar que a geografia acadêmica ocidental empreendeu um percurso de mais de dois mil anos de forma a satisfazer, de maneira organizada e disciplinada, a curiosidade inata das pessoas acerca dos lugares.

Embora não haja evidencias de que os filósofos pré-socráticos separassem as esferas cognitivas do real para fins de sua dissecação em separado, privilegiando interpretações totalizantes e místicas do mundo natural e dos feitos humanos, seus sucessores imediatos partiram por um outro caminho, do qual virá a emanar a própria dicotomia geográfica entre os estudos do mundo físico e/ou das ações humanas deliberadas sobre o espaço. A tradição sofista, ao separar physis de nomos, atribui uma atitude dicotômica para o tratamento do mundo físico, da psique humana e da realidade. Historicamente, a valoração em separado e privilegiada dos sentimentos e das ideias humanas talvez determine um ponto de inflexão que marca o surgimento pelo desprezo das coisas da natureza, não mais tidas como expressão da continuidade orgânica dos próprios homens, nem manifestações metafísicas insondáveis.

Com base nessa primeira digressão partimos para elaborar uma linha do tempo que simplificadamente abarque alguns rebatimentos importantes da história social do ocidente sobre o treinamento do geógrafo, em geral, e do geográfico físico em particular.

\section{Linha do Tempo}

De fato, a dualidade entre os dois maiores campos tradicionais da geografia parece residir no antagonismo vetusto, e já bem marcado no pensamento grego clássico, entre essência e matéria. É certo que os pré-socráticos inquiriam sobre todas as coisas. Os fragmentos de Heráclito nos mostram que esses filósofos tinham ideias sobre a natureza do mundo, englobando o que hoje definimos como física, química, geologia, meteorologia, astronomia, embriologia, e também psicologia, teologia e ética (CLARKE, 2018).

Neste momento, a raiz que definiria a epígrafe do que compreendemos como geografia física (Figura 1), a physis, é compreendida como a totalidade de tudo que há no mundo, ordenado ou não. De acordo com essa visão de mundo existira uma gênese mitológica das coisas, criadas pelos deuses. Da mesma forma, o mundo psíquico e suas normas também pertenceriam à physis. (CLARKE, 2018).

Se tomarmos Sócrates, Aristóteles e Platão como marcos do pensamento antagônico ao que descrevemos acima, podemos incluí-los como pais fundadores das proposições que contrapõem a natureza, o psíquico e o espiritual. A essa atitude podemos nos referir como Visão de Mundo Sofista, marcada pela separação antagônica entre physis (natureza) e nomos (leis, racionalismo). A mesma posiciona em esferas separadas do conhecimento os temas concernentes à natureza física, o mundo psíquico, e a seara espiritual. De certa forma, a popularização dessa atitude filosófica na Grécia a partir do século V a.C. talvez marque - para o mundo ocidental - a emergência da ideia de valorização do homem e suas ideias em detrimento ao conhecimento das relações de causalidade físico-naturais (CLARKE, 2018). As visões de mundo que acompanham as transformações do significado da natureza frente aos produtos culturais e às ideias, a partir da antiguidade clássica podem ser sintetizadas a partir das seguintes dualidades: 
* Influência Judaico-Cristã

$>$ Contraposição homem X natureza

$>$ Contraposição espírito X matéria

* Descartes, Sec. XVII

Pensamento pragmático-utilitarista, homem centro do mundo (sujeito)

* Iluminismo, Sec. XVIII

$>$ Crítica da metafísica em nome da física

* Sistematização acadêmica do conhecimento, Século XIX

$>$ Triunfo do mundo pragmático

* O estudo da natureza dividido em física, química, biologia, etc.

* Os "produtos" do homem em economia, sociologia, antropologia, história etc.

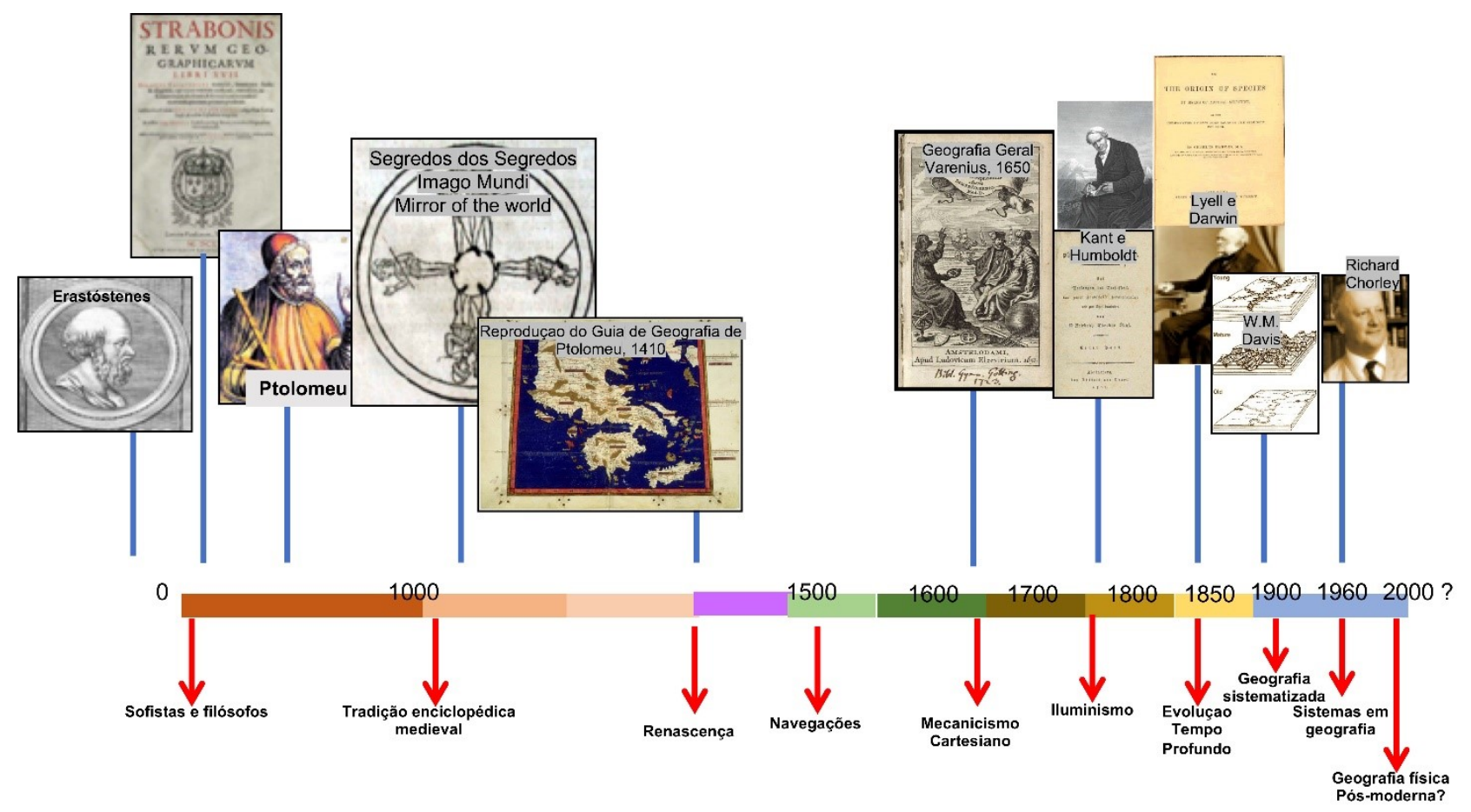

Figura 1. Antes do começo: as raízes da physis

Embora a contribuição clássica, grega, seja reconhecida como a origem da geografia ocidental moderna, assentando-se sobre as contribuições, por ordem cronológica de Heródoto (484-425 aC), Erastóstenes (275$193 \mathrm{aC}$ ), Estrabão (63aC-25dC) e Ptolomeu (100-178 dC), sendo ao primeiro atribuída a criação da epígrafe geografia, seus escritos contavam, por vezes em forma de mito, a descrição das terras e seus habitantes, ou seja, empreendiam uma crônica do ecúmeno então conhecido. Segundo Baker (2008), esses trabalhos tinham em comum a descrição dos lugares e seus componentes físicos (topographia) e sua interconexão "sistêmica", criando o que os gregos chamavam de chorographia, ou seja, o nascedouro de uma proto análise das regiões físicas do mundo conhecido.

\subsection{Alguns indícios do começo}

Sob a forma de um corpo sistematizado de conhecimento, a geografia teve poucos avanços até a renascença e a era das grandes navegações e descobertas. A geografia física dos escritos mais antigos de gregos, o acesso à avançada cartografia chinesa e seu instrumental de desenho e navegação na Itália do sec. XV, a popularização da visão proto-enciclopédica das compilações de autores árabes (AL MONAES, 1991), dentre outras contribuições, só começou a assumir forma de conhecimento acadêmico nas sociedades europeias entre os séculos XV e XVI. 
A tradução da "Geografia" de Ptolomeu (sec. II, d.C.) para o latim ca. 1410 popularizou a cartografia e a geodésia entre viajantes, exploradores e intelectuais, por meio de opulentas reproduções manuscritas e ilustradas, executadas sobretudo em Florença. Assim como os avanços técnicos da arte renascentista popularizou entre as elites europeias o gosto pela cartografia em edições ricamente ornadas, com as grandes navegações, a partir do sec. XV, verifica-se um significativo crescimento da valorização intelectual do conhecimento geográfico, aplicado tanto à exploração e ao descobrimento, quanto à classificação das novas formas de terras e vidas que se descortinavam. Sem dúvida, as inovações trazidas pelas grandes descobertas geográficas e técnicas daquele momento encorajaram a expansão formal da geografia. Sem dúvida, a mais significativa síntese desses avanços foi elaborada pelo médico alemão de Hannover, Bernhard Varenius (16221650), em sua Geographia Generalis, publicada em Amsterdam em 1650, pela editora Elsevier (VARENIUS, 1650).

A geografia de Varenius era um campo da matemática aplicada, considerando as propriedades quantitativas da Terra: forma, tamanho, movimentos e a distribuição e características das terras, água, montanhas, florestas, desertos além da atmosfera. Varenius compreendeu a geografia como subdividida em dois grandes subcampos: a geografia geral ou sistemática, e a geografia especial ou regional. De fato, o termo "Geografia Física" só aparecerá na literatura especializada a partir do séc. XVIII.

A geografia sistemática de Varenius estava voltada para a consideração das propriedades e processos em relação ao todo da terra, sem considerar as particularidades dos lugares e países. Já sua geografia especial tratava das propriedades e processos em operação nesses lugares e países. Ao definir um ramo da geografia voltado para o estudo analítico de conjuntos de formas e suas funções, Varenius abriu o caminho para o enfoque especializado de disciplinas que hoje integram a geografia física, como a geomorfologia.

Do ponto de vista do que hoje conceberíamos como geografia física, Varenius preocupou-se com a definição de leis gerais e sua demonstração, assim como a descrição de eventos relacionados à operação dessas (ex: movimento dos mares). Ressalta-se que o texto de Varenius era obrigatório em Cambridge na época de Isaac Newton, e fez parte do debate entre os sistemas cartesianos e newtonianos de ciência.

A origem da visão de mundo de Varenius está em dia e extremamente congruente com a divulgação nos meios acadêmicos da Europa do pensamento de Descartes (1596-1650). Segundo esse filósofo a natureza é constituída pela articulação de peças discretas, separadas, que se integram como as partes que compõem uma máquina. Assim, caberia ao homem individualizar as peças e reconstruir as relações entre elas, propiciando o pleno funcionamento da "máquina"; visão que se coaduna com a idéia de geografia geral, ou sistemática, onde as partes que integram o mundo devem ser estudas em separado para, por fim, reconstruir o todo (AKKERMAN, 2001). A visão mecanicista de mundo perpassará mais de dois séculos servindo de base conceitual para a geografia física compreendida como fisiografia.

O legado do filósofo prussiano Immanuel Kant (1724-1804) à geografia física em grande parte deriva das ideias de Varenius, sobretudo no que concerne à natureza dessa ciência. Para Kant, tanto a geografia quanto a história representam corpos de conhecimento sintetizadores (BAKER, 2008), sendo ambas descritivas, uma em relação à distribuição dos eventos no transcurso do tempo, e a outra no que diz respeito às circunstâncias espaciais. O conceito kantiano de Raum (lugar, espaço) tinha um caráter totalizador, ao qual se poderiam ser agregadas as descobertas realizadas nos campos sistemáticos, individualizados, da ciência, assim vindo a formar um todo.

Foram as palestras de Kant em Geografia Física (1756 a 1796) que definiram o escopo da disciplina: as condições naturais da Terra, montanhas, rios, minerais, plantas, etc. Kant afastou-se do aglomerado de informações pontuais baseadas na experiência cotidiana em busca de uma unidade "holística" do conhecimento, por fim liberada da "teologia natural". Para Kant a geografia física seria a descrição da natureza, ou do mundo como objeto apreendido pelos nossos sentidos exteriores.

Kant lecionou geografia física em Königsberg, Prússia, atual Kaliningrado, Rússia, a partir de 1756. Seu Esboço e Prospecto para um curso de geografia física (1757) foi uma tarefa voltada ao suprimento da lacuna de textos adequados na área. Com efeito, as notas de aula de Kant circularam por mais de 30 anos antes de serem reunidas em uma "Geografia Física" em 1802. 


\subsection{A Busca pelas Relações Causais}

Os desdobramentos que se seguiram à contribuição de Kant, como asseveram MacDonald e Withers (2015), estão bastante vinculados às inovações e disseminação do arsenal técnico cientifico a partir da segunda metade do século XVIII, dentre vários avanços podemos citar:

* Melhoria na determinação da posição geográfica:

* O cronômetro de Harrison em 1762;

* O barômetro (meados do sec. XVIII);

* O batímetro com sondas de chumbo;

* A utilização generalizada do método de Linnaeus para classificar organismos

Dentre os resultados reais do emprego desse novo arsenal tecnológico pode-se citar a bem sucedida chegada do Capitão Cook ao Pacífico em 1769, assim encerrando um grande ciclo de descobertas e incorporação de novas áreas do globo à esfera do ocidente, iniciado com as grandes navegações ainda no século XV (MacDONALD E WITHERS, 2015).

Munido do estado-da-arte do instrumental de navegação e levantamento de terras disponível àquela altura e de recursos para empreender uma grande viagem à América tropical, Alexander Von Humboldt lançou os fundamentos, enfim empiricamente controlados, para o estabelecimento de vínculos causativos para a distribuição das formas de vida sobre a Terra. A partir de Humboldt, a distribuição zonal e altitudinal da vegetação, como função dos diversos climas substitui a ideia de distribuição aleatória, comandada pelos desígnios divinos. Abre-se o caminho para os postulados de Darwin e Wallace sobre a evolução das espécies.

A expedição de Humboldt à América do Sul e Central foi financiada com meios particulares e tinha exclusivamente objetivos científicos. Além dos resultados de pesquisa, fundamentados nos novos métodos de medida e elaboração quantitativa acima enunciados, a viagem proporcionou relatórios geográficos integrando fatos socioeconômicos e políticos para além da própria geografia física, tendo como base a pesquisa empírica de campo (GUARÍN, 2004).

De acordo com Buttimer (2001), em seu "Essai Politique sur le Rayaume de la Nouvelle Espagne" Humboldt incluiu informações sobre a ecologia, clima, vegetação, mas também debateu as condições socioeconômicas e políticas. De todos os "pais fundadores" da geografia física, Humboldt foi o mais veemente no estabelecimento de interações entre as esferas do mundo físico-natural com as esferas da sociedade.

\subsection{Outras Perspectivas até Meados do Sec. XIX}

A expansão do conhecimento geográfico e sua popularização, levou à publicação diversas obras de divulgação, sobretudo voltadas para o ensino, tanto nas cátedras de geografia física que já se consolidavam nos principais centros universitários, quanto para suprir as necessidades da geografia no ensino básico. Dentre várias podem ser destacadas as obras Physical Geography, de Mary Sommerville, na Grã Bretanha em 1848; Earth and Man, publicado em 1849, do suíço Arnhold Henry Guyot, ex-aluno e discípulo de Ritter, que construiu sua carreira no College of New Jersey, EUA; e The physical geography of the sea do tenente estadunidense Matthew Fontaine Maury, lançada em 1855 e elogiada pelo próprio Humboldt (DRIVER E MARTINS, 2005).

Em comum esses trabalhos traziam a ênfase nas interconexões entre os fenômenos naturais como chave para a compreensão do funcionamento da natureza como um todo, refletindo muito mais a proposta mecanicista do que um suposto proto-sistemismo. Seus pontos fracos recaiam sobre a superficialidade e incoerência empírica das abordagens, muitas vezes focadas na tentativa de demonstrar interligações entre elementos díspares como a topografia, clima, minerais e os tipos humanos e formas de governo. De fato, todos esses trabalhos retratam um mundo pré-darwiniano, no qual as concepções de tempo ainda restavam atreladas, em grande medida, às visões da teologia científica, especialmente marcada pela forte influência da igreja anglicana e do calvinismo sobre as ciências naturais. 


\subsection{Geografia Física pós-Darwin}

Se da fase inicial de sistematização restou ao treinamento do geógrafo físico a busca pelas relações de causalidade no espaço, em uma tentativa de refazer o mosaico contemporâneo de organizações espaciais físicas, o período subsequente traria o elemento que buscava explicar a dinâmica dessas organizações; o tempo. Essa mudança no tratamento dos objetivos da análise em geografia física reflete o cenário de mudanças sociais rápidas do último quartel do século XIX.

Questões emergentes em áreas do conhecimento aparentemente não correlacionáveis como a demografia e a geologia serviram de base para uma mudança radical de paradigmas interpretativos que passaram da busca por relações causais para o reconhecimento das transformações no tempo e suas reverberações sobre o espaço, ou seja, a evolução dos processos formadores da paisagem física.

A obra do naturalista Charles Darwin sintetizou esse espírito de transformação e repercutiu diretamente sobre as nascentes disciplinas que compõem o que compreendemos como geografia física. Não obstante, é fundamental recompor de forma sintética o campo de forças intelectuais que forjaram essa tremenda mudança de foco nas ciências da terra, de uma preocupação inicial em elaborar tipologias e esquemas classificatórios, para uma visão que passaria a priorizar as narrativas históricas e o transcurso do tempo.

O impacto da contribuição de Darwin sobre o estabelecimento das bases científicas da geografia física foi tão significativo, que segundo as palavras de Sttodart (1966) essa sequer conseguiria ter se consolidado dentro do cenário das disciplinas acadêmicas não fosse a adoção da perspectiva de tempo como prevista por Darwin para a evolução das formas de vida. A relação "tempo x mudança da forma" passa então a guiar a maior parte dos emergentes programas de pesquisa nas subáreas da geomorfologia, pedologia e biogeografia.

Ainda sobre as obras que influenciaram diretamente a condução teórica das proposições de Darwin, podese citar inicialmente os "Princípios de Geologia" de Charles Lyell (1830/1833). O marco inovador deste trabalho basilar para as ciências da terra recai na noção de que as paisagens podem ser explicadas a partir dos processos operantes no tempo presente, ideia sintetizada pela epígrafe do atualismo. O outro desdobramento igualmente significativo desta contribuição diz respeito ao fato de que para imprimirem o resultado de seu trabalho sobre a superfície do planeta, a atuação dos processos físicos, com base nas taxas de operação dos fenômenos atuais devidamente observados, demanda sua operação pelo longo tempo geológico.

Por outro lado, foi o "Ensaio sobre o Princípio de População", (MALTHUS, 1798) que aportou a Darwin ideias-chaves tais como a noção de desequilíbrio e sobre-população (VORZIMMER, 1969). A primeira asseverando que a pressão da população é infinitamente maior que o poder da terra em prover sustento para os homens. Enquanto a segunda critica o otimismo dos seus contemporâneos e alerta para o perigo de excesso de população impedindo o que Malthus chamou de "felicidade duradoura do homem".

A mudança de premissas norteadoras na condução do pensamento sobre a natureza, presente na obra da Darwin, anuncia uma excepcional transformação da visão de mundo. Saía-se então de um cenário no qual proposições sobre a Terra e sua dinâmica superficial, que mesmo já balizadas por experimentos empíricos cujos princípios físicos passavam a ser compreendidos, chegavam a estabelecer, tais como as do Arcebispo James Ussher, Primaz anglicano da Irlanda (1625-1656), com base na exegese bíblica, que a Terra fora criada na noite anterior ao dia 23 de outubro de 4004 a.C (FEHIGE, 2016). A esse tipo de visão conciliadora entre a experimentação científica e a catequese anglicana, contrapõe-se a partir da sistematização das leis geológicas propostas por Lyell, a ideia de um tempo profundo de atuação dos processos físicos sobre a superfície do planeta, cujos indícios do seu princípio não eram prontamente discerníveis na paisagem.

Ainda que contemporaneamente a visão do passado que o presente nos proporciona seja reconhecidamente limitada, como bem externado pelo paleontólogo sueco Stefan Bengtson, em sua máxima em desafio ao atualismo clássico de Lyell: "o presente está mais para o buraco da fechadura do passado do que para chave", a ruptura com uma visão teológica, e logo necessariamente teleológica sobre a história da Terra representa uma alteração completa na forma como os processos naturais passam a ser compreendidos (BENGTSON, 1994). As repercussões dessa revolução no olhar sobre o tempo e suas novas dimensões refletem-se ainda sobre as discussões atuais entre o papel do homem como agente protagonista da transformação das paisagens ou mero observador de processos operantes em escalas de magnitude muito além de sua capacidade de interferência.

A despeito dos avanços sobre a compreensão dos fenômenos naturais, e a elucidação de relações de causalidade controlando a distribuição espacial de elementos componentes da paisagem, a geografia física prédarwiniana é essencialmente mecanicista e trata os componentes da natureza como integrantes de um mundo harmônico e diligentemente integrado. Restava ainda espaço para digressões otimistas acerca da intervenção 
divina sobre a organização dos processos, elemento que se revela na ainda forte predominância de modelos teleológicos de compreensão do mundo natural.

Por seu turno, as ciências da terra e por consequência a geografia física, a partir de Darwin, não apenas reconhecerão que de fato há interconexões no mundo natural, mas passarão a compreender que essas também possam ser vistas em função do desequilíbrio que estabelecem entre os elementos que o compõem (STODDART, 1966); conflito e diversificação das formas de vida e, metodologicamente, a emergência da primazia da necessidade de observação direta das interações bióticas e abióticas (ecologia).

Assim, a geografia física passa a ser o estudo do arranjo final da superfície terrestre, bem como essa se encontra no estágio atual de organização espacial, o qual resulta do somatório de processos de transformação no tempo. Embora a ideia de causalidade/interconexão entre os fenômenos mantenha e garanta a perspectiva de unidade do mundo físico, seus sistemas passam a ser compreendidos com base nos movimentos e mudanças ocorridos no longo transcurso do tempo geológico.

Certamente um dos primeiros desdobramentos concretos da mudança de perspectiva sobre os estudos da paisagem física decorrente da introdução da variável temporal emerge na contribuição do geomorfólogo William Morris Davis. A partir da construção do seu Ciclo Geográfico de evolução do relevo, o autor repôs os estudos de fisiografia - distribuição estática dos elementos integrantes da paisagem - pelo estudo ordenado de sua evolução temporal, sintetizados no aforisma:

“...o tempo possui a aplicação mais frequente e o maior valor prático"

(DAVIS, 1899)

Não obstante, o abandono da busca das relações de causalidade espacial e construção de tipologias do mundo físico em prol da construção de modelos unicamente temporais e, em larga escala, dedutivos de distribuição de formas cronocorrelatas de relevo levou em poucas décadas ao esgotamento da proposta davisiana. Assim, segundo Chorley (1965) o conceito de tempo progressivo, irreversível e ordenado de Davis, o levou ao estudo da história das paisagens, mais do que ao estudo das paisagens em si mesmas. Essa atitude metodológica equacionou os estudos de evolução e dinâmica da superfície do Planeta com o especializado e restrito campo da cronologia da denudação, pelo qual a história de paisagens inteiras poderia ser reconstruída com base na suposta identificação de superfícies de aplainamento.

No entanto, a crítica à Davis só surgiria após uma significativa mudança de paradigma metodológico na geografia física a partir da segunda metade do século XX, em grande parte influenciada por avanços técnicos e instrumentais na aferição dos processos de superfície. Assim, no interstício de mais de quarenta anos desde sua divulgação inicial na última década do século XIX a proposta davisiana extravasou o âmbito da geomorfologia e influenciou desde a nascente ciência dos solos, a partir da perspectiva dos solos zonais, à biogeografia de Clements (1916) com a noção de sucessão biológica em direção à comunidade clímax.

\subsection{Enfim a Profissionalização...}

É neste mesmo momento, no entanto, de disseminação das abordagens evolutivas em geografia física mediadas pela extrema valorização do tempo sobre as demais variáveis causais da organização espacial dos fenômenos físicos - que também passa a se consolidar a formação dos primeiros profissionais especializados nessa ciência, desta feita por meio do estabelecimento das primeiras iniciativas acadêmicas de sistematização de cursos de graduação em geografia. A Alemanha estabelece o primeiro departamento de geografia em Berlim em 1874 e em 1903 a Universidade de Chicago abre o primeiro dos Estados Unidos. (DUNBAR, 2001).

Segundo Brian (1944) a profissionalização do geógrafo e sua formação em geografia física até meados do século XX estaria a mercê de algumas circunstâncias históricas, tais como o fato que até aquele momento maior parte do mundo não havia ainda sido explorada por meio de levantamentos sistemáticos. Neste sentido, ressaltava-se ainda o papel das sociedades geográficas, centros de pesquisa e universidades que àquela altura deram prosseguimento à coleta de dados e estabelecimento de um inventário básico de informações físicas sobre as diversas áreas do planeta. Dentre essas destacam-se a determinação da altitude das superfícies geomorfológicas, classificação e descrição do relevo, medição da vazão dos rios e dos fenômenos climáticos e meteorológicos; classificação dos solos, organismos e determinação das comunidades sucessionais de vegetação. 
Igualmente, em 1956, em seu ensaio clássico, sobre a formação do geógrafo, Carl Sauer chamava a atenção para o papel do trabalho de campo e da geomorfologia como disciplina que possibilitava o exercício de tecer relações espaciais e causais a partir da observação da paisagem. Com base no cotejamento das obras desses autores pode-se definir um rol de ferramentas tradicionais para o exercício profissional da geografia física até meados do século passado (SAUER, 1956). Essas estavam especialmente relacionadas aos estudos de ordenamento territorial com fins de classificação, geralmente em escalas pequenas, destacando-se:

* Trabalho de campo priorizando grandes percursos e descrição narrativa da paisagem;

* Aerofotogrametria e técnicas qualitativas de sobreposição de informação espacial; criação de overlays;

* Aferição macroscópica de elementos estruturadores da paisagem (rochas, solos, vegetação, formas de uso da terra)

* A fotografia aérea, em gabinete, e o mapa topográfico, em campo, como base do posicionamento geográfico.

Obviamente este arsenal técnico esteve atrelado a uma série de objetivos e interações disciplinares tradicionais, que refletem um determinado momento histórico. Sob o ponto de vista teórico, pode-se sintetizar os encaminhamentos da formação em geografia física a partir de uma noção global do controle exercido pelo tempo sobre o espaço. Assim, os objetivos da produção acadêmica e aplicada nesta ciência estiveram voltados à busca pela identificação de padrões normais de evolução dos arranjos espaciais físico-naturais, estabelecimento de padrões sucessionais no caso das comunidades de organismos, encadeamento cronológico das formas de relevo, de maneira a ajusta-las aos esquemas pré-estabelecidos de distribuição e desenvolvimento morfológico da superfície terrestre.

No âmbito das aplicações voltadas ao planejamento de áreas destacam-se os relatórios voltados a descrever, inventariar e regionalizar parâmetros individuais da paisagem e a construção de cartas-base para a intervenção em grandes escalas espaciais. Quanto às interações disciplinares destacam-se as aproximações, tanto no âmbito da formação acadêmica quanto da prática profissional aplicada, com a biologia e pedologia taxonômicas, geologia geral, cartografia analítica, meteorologia e climatologia estatística (DUNBAR, 2001).

Sem estabelecer um limite cronológico preciso para uma mudança de paradigma na formação em geografia física, mas circunstanciando essa passagem face à inserção crescente da abordagem sistêmica nas ciências físicas e da terra a partir da década de 1960, constata-se a emergência de novos objetivos a serem alcançados a partir da abordagem geográfica dos fenômenos físicos. Gradativamente, a alternância de enfoques acaba por tornar os objetivos da fase anterior obsoletos, ainda que a resiliência de algumas abordagens tradicionais tenha sido particularmente notável na academia, garantindo uma sobrevida inusitada a perspectivas tais como a cronologia da denudação, a despeito da dificuldade empírica de sua validação. $\mathrm{O}$ foco então do treinamento em geografia física sai da cartografia dos atributos naturais da paisagem para a compreensão do funcionamento do mundo "natural" físico.

\section{O Sistema Como Linguagem Geográfica: A Semântica de Um Novo Paradigma}

A fim de dar conta das demandas de um novo mundo de complexidade e interações, o praticante de geografia física a partir de meados da década de 1960 deveria estar apto a investigar e descobrir as leis que regem processos e comportamentos dos atributos físicos da paisagem e suas organizações espaciais próprias. Em termos filosóficos, diante da substituição de uma atitude racionalista crítica por uma postura relativista, dentro da compreensão de ciência proposta por Kuhn (2012), pode-se dizer que o objetivo da geografia física passou a ser a busca pela solução de problemas, na escala dos processos de superfície terrestre, mediante ou não a interação direta com os moduladores antropo-sociais, e não a busca de uma verdade sobre as relações causais de distribuição dos padrões espaciais da natureza. Essa transformação no olhar sobre o mundo físico é acompanhada da aceitação de que não existem fatos independentes da teoria, nem uma "realidade claramente objetiva", sobretudo em uma ciência cujos limites experimentais estão muito afastados, no grau de acuidade e replicabilidade, daqueles da mecânica dos sólidos ou da biologia-molecular. 
Assim a entrada da linguagem sistêmica como base metodológica para a pesquisa em geografia física vem necessariamente acompanhada da aceitação de que um novo paradigma representa um consenso dos objetivos, métodos, práticas, crenças e tradições científicas que definem a "ciência normal" num dado lapso de tempo. Esta mudança de atitude procedimental diante do fato físico-natural e até da linguagem usada para descrevelo define os padrões e objetivos para a pesquisa considerada relevante, e por fim reproduz-se na academia por meio da iniciação e treinamento de estudantes na nova "emergente" tradição.

Desta forma, o surgimento e avanço da abordagem sistêmica em geografia física pode ser compreendido como uma substituição do paradigma da geografia física clássica por outro e não pela acumulação dos avanços da fase anterior. Objetivamente, a escolha por um novo método de se fazer geografia física constituiu para muitas escolas um ato de fé, e práticas recalcitrantes se mantiveram a despeito da dificuldade crescente dos seus resultados dialogarem com uma florescente base de dados em cunho sistêmico. Assim, ao se perguntar porque a cronologia da denudação não foi substituída por nenhuma outra grande teoria sobre o desenvolvimento do relevo, nenhuma outra grande meta-narrativa explicativa sobre a origem de supostos níveis de superfícies de cimeira, pode-se simplesmente aventar como resposta o fato de que a partir de do final da década de 1960 houve uma mudança total nos objetivos da pesquisa geomorfológica, e a busca pelo significado e origem das superfícies de aplainamento já não estava na ordem do dia. Pelo menos não diante do arsenal técnico então disponível para gerar dados empiricamente robustos.

Pois sim, a técnica passa cada vez mais a definir o temário das investigações, sobretudo em um cenário em que a renovação da base tecnológica disponível para aferição dos fenômenos naturais passou a se redefinir a cada década, ou intervalos menores dentro delas. O que nos leva ao questionamento essencial sobre se de fato presenciou-se a emergência de um novo paradigma na geografia física ou apenas o progresso na capacidade de "resolver problemas" a partir da revolução técnico-informacional, que substituiu décadas de cartografia analógica por bases de dados georreferenciados digitais de manipulação altamente flexível, e, recentemente, o barômetro e a bússola pelos sensoriamento remoto ativo dos laser scans.

Uma diferença fundamental da geografia física pós introdução da noção de sistemas, para compreensão dos atributos e operação de processos no mundo físico, se deu por uma mudança na semântica do seu glossário de expressões explicativas. Ou seja, em grande parte a geografia física passou a adotar terminologias adequadas à aferição dos estados dos processos na superfície terrestre, não mais em função de uma cronologia evolutiva, ou pelo menos não unicamente dependente dessa, mas também em função da escala de tempo de observação dos fenômenos estudados, sua duração, magnitude e possibilidade de recorrência. Assim palavras como juventude, maturidade e clímax, perdem sentido pois existiriam na dependência de uma cronologia linear absoluta e não da possibilidade de repetição exaustiva de eventos muito similares em origem e capacidade de atuar sobre a transformação da paisagem (CHORLEY E KENNEDY, 1971).

A mudança acima enunciada veio munida de desdobramentos distintos para as escolas geográficas que passam a usar a compreensão não finalista do tempo mas o emprego de recortes temporais ajustados, customizados, à necessidade das análises e solução dos questionamentos propostos. Em sua grande maioria, como dito acima, a mudança de atitude diante da análise dos fenômenos e propriedades físicas se expressa nos ajustes metodológicos e na escolha terminológica para precisar as medições realizadas, dentro de uma perspectiva de sistemas processo-resposta. Neste sentido, poucos avanços foram tentados do ponto de vista da criação de tipologias físico-naturais de caráter funcional, restando a cartografia dos fenômenos construída sobre bases tradicionais de delimitação de áreas. Por outro lado, uma escola baseada na cartografia da dinâmica de interrelação dos atributos físicos da paisagem, e mediante a aferição de estados mutantes de comportamento propõe a individualização de unidades territoriais funcionais, sob a epígrafe de abordagem geossistêmica sobretudo junto às tradições eslavas e francófonas de geografia (BERTRAND, 1972) - e, em alguma medida, conquanto cartografia da paisagem e sistemas de terras nas escolas anglo-saxãs (SWAFFIELD E O'CONNOR, 1986).

No entanto, a mediação dos trabalhos geográficos por plataformas automatizadas de processamento geoespacial também passou a demandar a capacidade de se prever cenários futuros. Obviamente, a mudança de foco e objetivo passa também a ser conduzida pela capacidade crescente da geografia física em utilizar-se do método científico para demonstrar os resultados alcançados pelo uso de uma infinidade de novas técnicas de aferição das propriedades do mundo físico.

Diante deste novo cenário, e para além da clássica classificação de áreas, agora em bases automatizadas, as ferramentas da geografia física estão sobretudo voltadas à aferição de processos funcionais e pretéritos, responsáveis pela distribuição e estruturação hierárquica dos elementos que integram a paisagem, inclusive aqueles cujos parâmetros físicos foram transformados ou condicionados pelas ações da sociedade. 
A abordagem estritamente espacial e de cunho cartográfico passa a depender da aplicação do sensoriamento remoto orbital em bases de SIG sob diversos contextos temáticos, com sobreposição temporal de imagens, aplicação de índices morfométricos e de reflectância buscando ressaltar aspectos e propriedades espaciais particulares inerentes aos parâmetros físicos da superfície e seu recobrimento. Por seu turno, o trabalho de campo voltado à coleta de amostras (rochas, sedimentos, solos, vegetação etc.) continua sendo um elemento essencial para a aferição das dinâmicas espaço-temporais e relações de causalidade na distribuição de propriedades inerentes aos materiais que estruturam a paisagem.

Da mesma forma, as transformações sociais e a emergência de novos problemas e realidades espaciais, sobretudo a partir da década de 1960, conduziram ao surgimento de um novo repertório de objetivos para a geografia física, que demandou ajustes metodológicos adequados à mudança de paradigma teórico que se estabelece e se consolida. Um desses enfoques, que aporta de forma extensiva as bases metodológicas da teoria sistêmica, sobretudo no que tange à aplicação da variável tempo, é o que concerne as mudanças ambientais globais (de cunho antrópico ou não), percebidas a partir da quantidade de transformação que essas agregam à estrutura física das paisagens (SLAYMAKER et al., 2012).

Observa-se então, em todas as sub-áreas temáticas dessa ciência a valorização dos processos sobre o tempo na distribuição dos fenômenos físicos no espaço. Neste novo contexto de objetivos e busca por resultados, o tempo passa a desempenhar um papel de mediador da análise espacial de acordo com a escala e recorrência dos fenômenos, mas já não representa o sentido da explicação em si. Igualmente surgem linhas inteiras de investigação voltadas à construção de análises integradoras e aplicadas voltadas à resolução de situaçõesproblema (ex: impactos ambientais urbanos).

Assim, por exemplo, a biogeografia de cunho evolutivo e taxonômico passa a se debruçar sobre a avaliação de sensitividade ambiental e monitoramento de áreas, direcionando também seus esforços de pesquisa para a análise, avaliação e gestão do risco ambiental. Sendo essa última aplicação também compartilhada pela geomorfologia aplicada. Seguindo ainda nessa linha de encaminhamentos, em face das transformações sociais e da emergência de novos problemas e desafios ambientais a serem encarados pelos estudos biogeográficos, verifica-se assim uma mudança das interações disciplinares, com destaque para a crescente aplicação do sensoriamento e imageamento remoto com controle temporal dos fenômenos associados à cobertura da terra; como por exemplo, as transformações sazonais na cobertura vegetal.

Por outro lado, a reconstrução de dinâmicas físico-espaciais na escala da paisagem, considerando a interação sistêmica entre seus elementos estruturadores, e aferição empírica das trocas atuais e pretéritas de energia e material entre os compartimentos e estimativa das taxas de mudanças ao longo do tempo, abre espaço também para a projeção e modelagem de cenários futuros em diversas escalas de interação. Em face da maleabilidade da abordagem sistêmica, esse tipo de análise prognóstica permite mesmo estabelecer limiares e magnitudes para mudanças ambientais em escala global.

A biogeografia, mediada pelos avanços da biologia evolutiva, da bioquímica aplicada e da modelagem matemática também parte para a busca de explicações mais robustas e empiricamente comprovadas dos mecanismos de dispersão e colonização de áreas pelos organismos. Um exemplo desse tipo de aplicação em base de modelagem construída por meio do uso de SIGs diz respeito ao cálculo preditivo de biodiversidade futura, em função da relação "área x espécies" em cenário de mudanças climáticas globais (O'DWYER E GREEN, 2009). Por fim, e sobretudo a partir da década de 1990, observam-se importantes mudanças na condução das narrativas de pesquisa, com a integração do conhecimento científico aos diversos tipos de saberes, inclusive os das comunidades tradicionais à mercê das transformações físico-espaciais (DIXON, 2003). Essa vertente de estudos, abre o diálogo com a antropologia cultural e agroecologia por meio de trabalhos voltados à compreensão de mecanismos de dispersão de cultivares e manutenção da biodiversidade em comunidades tradicionais.

Os demais campos da geografia física, nos quais os estudos processuais já haviam há algumas décadas suplantado as análises de cunho regional e de compartimentação de áreas passaram a se beneficiar das aplicações de métodos de geoquímica aplicada à paisagem, tais como as análises isotópicas e radiométricas voltadas à datação e análise de propriedades físicas e químicas dos materiais. Ressalta-se ainda colaboração entre geomorfologia e pedologia por meio da emergência dos estudos que visavam elucidar o papel dos mantos de intemperismo na gênese de longo prazo do relevo - análise estrutural das coberturas edáficas ; além da retomada da interação com a geologia, sobretudo a estrutural, abrindo caminhos para o campo da morfotectônica (MASOUD E KOIKE, 2011), no qual os processos estruturadores das formas de relevo são analisados inicialmente a partir dos esforços mecânicos de deformação da superfície da crosta terrestre. O uso extensivo de modelos digitais do terreno, com extração automática de fotolineamentos permitiu uma 
verdadeira retomada dos estudos morfométricos do relevo, cujas bases conceituais e metodológicas haviam sido lançadas ainda na década de 1950 pelos trabalhos clássicos de Strahler e Hack.

Outros campos da geografia física como a climatologia, que por muito tempo se dedicara à aplicação de sistemas de classificação climática, aproxima-se da meteorologia dinâmica, buscando estabelecer análises rítmicas dos sistemas causadores de tempo e definição de eventos extremos cujos impactos são absorvidos ou não pelas organizações espaciais (CARREGA, 2013). Este tipo de aplicação abriu espaço para estudos de risco ambiental climático amparados pela crescente utilização de produtos de sensores remotos.

Estudos transdisciplinares também começam a tomar espaço na geografia física voltada à reconstrução da história das paisagens, e suas paleo-geografias. Neste caso as aproximações teóricas e procedimentais vão incorporar a colaboração com a arqueologia e a micro-paleontologia, por meio do estudo dos palinomorfos e biomineralizações presentes nos sedimentos quaternários que estruturam a superfície da paisagem.

\subsection{A Geografia Física após a Teoria dos Sistemas}

Quase cinco décadas após a disseminação da semântica sistêmica na geografia física, mais que puramente um método sistêmico - já que esses foram vários - é factível estabelecer uma periodização desta fase histórica na nossa ciência. O primeiro momento ainda claramente positivista-racionalista, esteve muito mais voltado ao refinamento dos procedimentos técnicos de forma que as hipóteses de trabalho pudessem ser testadas mediante o rigor de várias escalas de experimentação, assim novas variáveis de controle poderiam emergir da continua crítica e desconstrução da hipótese mestra. Essa fase fortemente elusiva quanto ao caráter geográfico dos seus produtos levou à diatribe ainda hoje repetida pela geografia humana de que abordagem sistêmica seria reducionista e mecanicista.

A reação que se seguiu, com certa contemporaneidade à geografia crítica, postulava uma geografia física aplicada, ou realista. Assim a contraposição irreconciliável entre sociedade e natureza parecia haver alcançado por fim uma trégua em face de estudos "bem intencionados" capazes de minimizar ou mitigar os efeitos nocivos do natural sobre o social e vice-versa. A dificuldade encontrada neste rationale, válida até hoje, é a recorrente frustração na emergência de modelos explicativos, que não sejam altamente contingenciados pela própria diversidade geográfica do espaço, e, portanto, irreplicáveis conquanto criações científicas metodologicamente "puras", sob o ponto de vista físico experimental.

Sem contar com um arcabouço seguro de leis em bases físicas que permita prever cenários para além dos seus próprios estudos de caso e dos limites impostos pelos forçantes históricos, sejam estes naturais ou sociais, a geografia física tem ainda assim demonstrado a capacidade de se liberar de expectativas inalcançáveis de retidão metodológica e obediência aos procedimentos das ciências experimentais de reprodutibilidade laboratorial. Essa tendência, ainda fortemente lastreada pela ruptura sistêmica e mediada pelo seu vasto glossário de expressões de aferição de estado e expectativa temporal de repetição do evento, tem se definido cada vez mais como uma visão sobre o real com finalidade explicativa não finalista, mas fortemente narrativa e, muitas vezes recorrendo a procedimentos históricos de explicação dos fenômenos.

\section{Da Inveja À Explicação do Mundo}

Sem querer aderir à pós-modernidade totalizante das práticas culturais e acadêmicas que emergiu com muita eloquência a partir da década de 1990, quando toda a explicação poderia ser flexível e abrangente a fim de acomodar narrativas divergentes sem considerar as basilares diferenças de método, acreditamos que mesmo a partir de uma construção não totalmente pós moderna, a geografia física continua sendo um tipo de explicação sobre a materialidade do mundo real em sua expressão espacial, natural e física. Em concordância com Clifford (2001), a negação da explicação, antes da emergência das atitudes relativistas do que se aceita hoje em dia como prática científica, levara a primeira leva de geógrafos sistêmicos a considerar fútil e pedestre qualquer raciocínio que não pudesse ser integralmente desconstruído. Por outro lado, o utilitarismo e proselitismo, em prol de uma geografia física aplicada pós década de 1980 exacerbou, na busca pela solução de problemas por meio da aplicação de modelos mediados pela instrumentação em bases digitais e ensaios experimentais em simplificações escalares duvidosas, o que Massey (2012) diagnosticou como uma irremediável inveja da física por parte de um expressivo grupo de geógrafos físicos. 
A inveja da linguagem robusta e versatilidade explicativa das leis físicas, segundo a autora inglesa, tornara muitos trabalhos de geografia física antes em um louvor ao método que uma busca sincera pela compreensão de um evento geográfico. Embora existam aqueles que, como Massey (2012) e Diamond (2005) flertem com o caráter de ciência histórica como o elemento chave de afirmação da narrativa em geografia física e até mesmo, de acordo com a primeira, de reconciliação desta com a geografia humana, preferimos finalizar esta contribuição aceitando que a geografia física é um tipo de narrativa espacial. Como toda narrativa ela nos oferece uma explicação, e como essa se processa dentro de um dado recorte de tempo histórico-social, tende a ter um aspecto desconfortavelmente fugidio e efêmero, sobretudo quando se tenta enquadrar com demasiado rigor o alcance do seu escopo e as intenções finais dos seus praticantes.

\section{REFERÊNCIAS}

AGASSIZ, L.; AGASSIZ, E. 1868. A Journey in Brazil. Boston: Ticknor \& Fields.

AKKERMAN, A. 2001. Urban planning in the founding of Cartesian thought. Philosophy \& Geography, Volume 4, Issue 2, pp. $141-167$.

AL MONAES, W. A. 1991. Muslim contributions to geography until the end of the 12th century AD. GeoJournal. Volume 25, Issue 4, pp 393-400

BAKER, V. R. 2008. The Spokane Flood debates: historical background and philosophical perspective, Geological Society, London, Special Publications, 301, 33-50

BENGTSON, S. 1994. Early Life on Earth. Columbia University Press, 630 p.

BERTRAND, G. 1972. Paisagem e geografia física global: um esboço metodológico. Revista IGEOG/USP, São Paulo: USP, n. 13. Caderno de ciências da terra.

BRIAN, K. 1944. Physical Geography in the Training of the Geographer. Annals of the Association of American Geographers, Vol. 34, No. 4, pp. 183-189

BUTTIMER, A. 2001. Beyond Humboldtian Science and Goethe's Way of Science: Challenges of Alexander von Humboldt's Geography. Erdkunde 55(2): 105-120

CARREGA, P. 2013. Geographical Information and Climatology. Wiley, 288 p

CHORLEY, R.J. 1965. A re-evaluation of the geomorphic system of W.M. Davis. In: CHORLEY, R.J. e HAGGET, P. (eds) Frontiers in geographical teaching. London: Methuem, p. 21-38

CHORLEY, R. J., \& KENNEDY, B. A. 1971. Physical Geography: A systems approach. London: PrenticeHall International. 370 p.

CLARKE, K. 2018. Shaping the Geography of Empire: Man and Nature in Herodotus' Histories. Oxford Press, $368 \mathrm{p}$.

CLEMENTS, F. E. 1916. Plant Sucession. Carnegie Institution, Publication 242, Washington D.C.

CLIFFORD, N. 2001. Editorial: Physical Geography - the naughty world revisited. Transc. Inst. Brit. Geogr.

CONTI, J. B. 2005. Considerações sobre as mudanças climáticas globais. Revista do Departamento de Geografia, 16. Pg 70-75.

DARWIN, C. 1839. The Voyage of the Beagle. London.

DAVIS, W. M. 1899. The Geographical Cycle. In: Geographical Journal of The Royal Geographical Society. V. 14. N 5. Pg. 481-504.

DIAMOND, J. 2005. Collapse: how societies choose to fail or succeed. New York: Penguin, 626p

DIXON, C. 2003. Historical Etnobiogeography of the Spread of Lethal Yellowing in the Western Caribbean. Annual Meeting of the Association of American Geographers, New Orelans, LA.

DRIVER, F; MARTINS, L. 2005. Tropical Visions in an Age of Empire. University of Chicago Press, 279 p.

DUNBAR, G. S. 2001. Geography: Discipline, Profession and Subject since 1870. Springer Verlag, 336 p.

FEHIGE, Y. 2016. Science and Religion: East and West. Routledge India. 232 p. 
GUARÍN A. 2004. Alexander von Humboldt and the Origins of Our Modern Geographical View of Earth. In: JANELlE D.G., WARF B., HANSEN K. (eds) WorldMinds: Geographical Perspectives on 100 Problems. Springer, Dordrecht

KUHN, T. S. H. 2012. The Structure of Scientific Revolutions: 50th Anniversary Edition. University of Chicago Press. 264 p.

MACDONALD, F; WITHERS, C. W. J. 2015. Geography, Technology and Instruments of Exploration. Routledge. $282 \mathrm{p}$

MALTHUS, T. 1798. An essay on the Principle of Population. London.

MASOUDA, A \& KOIKE, K. 2011. Morphotectonics inferred from the analysis of topographic lineaments auto-detected from DEMs: Application and validation for the Sinai Peninsula, Egypt. Tectonophysics. Volume 510, Issues 3-4, 291-308.

MASSEY, D. 2012. For Space. London: Sage, 222p

MENDONCA, F. A. 1998. Geografia Fisica: Ciencia Humana? Sao Paulo: Contexto, 90p

O'DWYER, J.P.; GREEN. J. L. 2009. Field theory for biogeography: a spatially explicit model for predicting patterns of biodiversity. Ecology Letters, 13, 84-95

SAUER, C. O. 1956. The Education of a Geographer. Annals of the Association of American Geographers. V. 46. N.3.

SLAYMAKER, O.; SPENCER, T.; EMBLETON-HAMANN, C. 2012. Geomorphology and Global Environmental Change. Change. Wiley. 450 p.

STODDART, D. R. 1966. Darwin's Impact on Geography. Annals of the Association of American Geographers. Vol. 56, pp. 683-698.

SUERTEGARAY, D. M. A. 2002. Geografia Física e Geomorfologia: uma (re) leitura. 1. ed. Ijuí: Editora Unijuí, 112p

SWAFFIElD, S. R. \& O'CONNOR, K. F. 1986. Conceiving, Perceiving, Protecting and Using New Zealand Landscape Systems. Canterbury: Centre for Resource Management, Lincoln College.

VARENIUS, B. 1650. Geografia Geral-en la que se explican las propriedades generales de la tierra. 2.ed. Trad. José Maria Requejo Prieto. Barcelona: Ediciones de la Universidad de Barcelona, (1984).

VORZIMMER, P. 1969. Darwin, Malthus, and the Theory of Natural Selection. Journal of the History of Ideas. Vol. 30, No. 4, pp. 527-542 